\title{
Barras, policías y dirigentes. Sobre el gobierno de la seguridad en el fútbol argentino
}

\author{
José Garriga Zucal \\ Diego Murzi* \\ Sebastián Rosa ${ }^{* *}$
}

* Licenciado en Antropología, y doctor en Antropología social por la Universidad de Buenos Aires (UBA). Magister en Antropología social (IDES-IDAES/UNSAM). Actualmente, es investigador del CONICET, y docente de la Universidad Nacional de San Martín. Correo electrónico: garrigajose@ hotmail.com

** Licenciado Sociología, y doctor en Ciencias Sociales por la Universidad de Buenos Aires (UBA), Magister en Sociología por La Escuela de Estudios Superiores en Ciencias Sociales de París (EHESS). Actualmente es Postdoctorante del CONICET. Correo electrónico: diegomurzi@gmail.com

*** Licenciado en Sociología por la Universidad Nacional de La Plata. Becario doctoral del CONICET en el Instituto de Investigaciones en Humanidades y Ciencias Sociales (IDIHCS). Correo electrónico: sebastiangabrielrosa@gmail.com

Fecha de recepción: 07/04/2020. Fecha de aceptación: 14/06/2020. 


\title{
Barras, policías y dirigentes. Sobre el gobierno de la seguridad en el fútbol argentino
}

\section{Resumen}

En este artículo proponemos una reflexión sobre el rol del Estado en las formas de regulación de las violencias en el fútbol argentino a partir de un triple pacto que involucra a las «barras», la policía y los dirigentes deportivos. Para ello analizamos las tramas de intercambios entre estos actores. En este recorrido, analizamos la constitución de los modos en que se configura un acuerdo entre las partes que regula las violencias y gestiona la seguridad en el fútbol. En este acuerdo se habilitan la gestión de mercados ilegales y el desarrollo de procesos identitarios. Finalmente, nos interesa reflexionar sobe el rol del Estado en la gestión de la seguridad en el futbol.

Palabras clave: violencia, seguridad, fútbol.

\section{«Barras», police officers and sport officers. About the government of security in Argentinean football}

\begin{abstract}
In this article, we propose a reflection on the modes of regulation of violence in Argentine football based on a triple pact that involves «barras", police officers and sports leaders. We analyze for that the relationships and exchanges between these actors. Within this framework, we describe the ways in which a tacit pact is configured, with invisible links and interdependence logics through which violence is regulated and the security government is administered. Finally, we seek to show how these forms of interrelation and the legitimacy of certain violent actions enable the management of illegal markets and the development of identity processes.
\end{abstract}

Keywords: violence, security, soccer. 


\section{INTRODUCCIÓN}

¿Cómo se regulan las violencias en el mundo del fútbol argentino? Para responder a esta pregunta analizaremos las relaciones entre tres actores: las «barras», la policía y los dirigentes deportivos. Entre esos tres actores se generan vínculos e intercambios - en su mayoría invisibles - que configuran un pacto. Estas interacciones benefician a las tres partes, generando una interdependencia; los beneficios, materiales y simbólicos, de estos acuerdos se reproducen sólo cuando las violencias están reguladas. Así, el pacto regula y administra el gobierno de la seguridad en el fútbol argentino. La regulación que el pacto genera —inestable — habilita la gestión de mercados ilegales alrededor del fútbol.

Este trabajo es el resultado de la comparación y articulación de tres investigaciones. José Garriga Zucal realizó un trabajo de campo en 1999 con integrantes de la «barra» del club Colegiales y luego entre 2004 y 2008 otra investigación con miembros de la «barra» del Club Atlético Huracán, ambos en Argentina. En los últimos años colaboró en varias oportunidades con los encargados de planificación de políticas públicas para la prevención de la violencia. Sebastián Gabriel Rosa, por su parte, investigó a través del estudio de la prensa gráfica nacional la historia de la prohibición del público visitante y los discursos dominantes en el campo de la seguridad en el fútbol entre los años 2007 y 2015. También realiza trabajo de campo acompańando controladores y controladoras de admisión y permanencia en espectáculos masivos como partidos de fútbol y recitales en la ciudad de La Plata desde el año 2018. Finalmente, Diego Murzi ha analizado en su trabajo de tesis doctoral la historia de las políticas públicas de gestión de la violencia en el fútbol en Argentina entre 1983 y 2017. Para dicha investigación, realizó trabajo de campo en estadios de la Ciudad de Buenos Aires acompañando a las agencias de seguridad deportiva y a la policía entre 2015 y 2017.

Este artículo es el resultado del cruce de las experiencias etnográficas de los tres autores, que en distintos momentos a lo largo de los últimos 15 años han observado y analizado a los actores centrales de los fenómenos que se abordan en este texto: las «barras», los dirigentes y la policía. La amplitud temporal del período en que fueron hechas las observaciones permite que los procesos y mecanismos que describe el artículo puedan ser pensados como regulares y recurrentes, y no solo como una fotografía de una época acotada de trabajo de campo. Asimismo, la totalidad de las etnografías se hicieron en la Ciudad de Buenos Aires, en el conurbano bonaerense y en La Plata ${ }^{1}$.

\footnotetext{
Este trabajo es producto de una reversión y actualización de un texto presentado y realizado en conjunto por los autores bajo el título «El triple pacto. Del gobierno de la seguridad a la regulación de la
} 


\section{El GobIERNo DE LA SEGURIDAD}

En mayo de 2016 participamos de una reunión en el Ministerio de Seguridad de la provincia de Santa Fe entre policías que organizaban la seguridad en el fútbol argentino profesional. Allí, algunos de los policías mencionaron que estaban cansados de ser «el pato de la boda» y ser representados como «los malos de la película». Desde su perspectiva, eran señalados como responsables de todos los males en el fútbol argentino. Y renegaban sobre el lugar que ocupaban en los discursos mediáticos, de los dirigentes y de los hinchas sobre la seguridad en el fútbol, ya que planteaban era injustificado e injusto. Sin embargo, en ese contexto, varios señalaron a modo de reflexión su propia responsabilidad. Un policía con varios ańos de experiencia comentó que era "hora de sincerarnos», porque "nosotros negociamos con las barras», agregó ${ }^{2}$. Esto abrió el diálogo a que, a modo de catarsis, un gran número de agentes encargados de prevenir la violencia en el fútbol comenzaran a recordar y comentar las relaciones y las charlas que mantenían con los «barrabravas». Así, definieron al jefe de una de las «barras» como un «señor», en comparación con el «capo» de otro grupo, al que trataron de «barrilete»${ }^{3}$. En su experiencia, el diálogo y la negociación con los dirigentes de los clubes eran más complejos que con los miembros de las barras, ya que "los tipos cumplen con lo pactado".

En el escenario de la seguridad del fútbol profesional en la Argentina observamos una multiplicidad de actores que intervienen en mayor o menor medida: hinchas no pertenecientes a la «barra», funcionarios de diversas agencias estatales, jugadores y periodistas son algunos de ellos. Pero hay tres actores que son centrales, y sobre ellos nos interesa poner el foco en este artículo. Hablamos de los dirigentes deportivos, de las policías y de las «barras». Vamos a analizar ${ }^{4}$ estas relaciones como un triple pacto, que funciona como eje principal de la regulación de la violencia en los espectáculos futbolísticos en nuestro país.

En la Argentina, el despliegue operativo de la seguridad en los estadios de fútbol es organizado y ejecutado por las policías jurisdiccionales (la policía en la Ciudad

violencia en el fútbol argentino", en el libro Sufrir, matar y morir: contribuciones a la socio-antropología de las violencias y las muertes, coordinado por Laura Panizio y José Garriga Zucal y publicado en 2020.

2 Usaremos las comillas para los términos nativos «barras» $y$ «barras bravas», ya que son conceptos que condensan un fuerte repudio en la Argentina y hacen referencia al grupo organizado de espectadores comúnmente vinculado con la violencia. Observaremos que no son los únicos que protagonizan actos violentos, pero son, sin dudas, los que tienen prácticas violentas más visibles.

3 «Barrilete» es un término del habla popular de Buenos Aires que se usa para designar a una persona cuyo discurso es inconsistente con sus acciones, es decir, que dice que hará una cosa y luego hace algo diferente. Designa a alguien impredecible, poco confiable.

4 El análisis es posible por la acumulación de trabajos sobre el tema Pablo Alabarces (2004), José Garriga Zucal (2007), María Verónica Moreira (2005), Nicolás Cabrera (2013), Federico Czesli (2013), Diego Murzi (2019), Sebastián Rosa (2017) y Gastón Gil (2007). 
de Buenos Aires (CABA sus siglas), la Policía Bonaerense en la Provincia de Buenos Aires, etc.), materializado en lo que se conoce como «operativos de seguridad». Desde 2013, y sólo para algunos partidos jugados en la CABA, se incluyeron también en los operativos otras fuerzas de seguridad federales (Gendarmería, Prefectura, Policía Aeroportuaria).

Los policías que trabajan en los partidos de fútbol son denominados «efectivos» y cobran un dinero adicional a su salario por las tareas vinculadas con la seguridad. Dependiendo de la jurisdicción, muchos «efectivos» trabajan en los estadios luego de cumplir con su servicio diario, es decir, en calidad de «horas extras». El dinero del operativo de seguridad lo abonan los clubes deportivos, que de este modo ofician como contratantes del servicio de la policía, en una suerte de privatización temporaria de las fuerzas de seguridad públicas. Los encargados del operativo - altos mandos policiales - tienen, además, la potestad de interpretar la peligrosidad del evento y decidir, por ello, cuántos «efectivos» son necesarios para cada partido. De esa manera se produce un curioso proceso por el cual los clubes contratan a la policía (como suerte de actor privatizado) pero es la propia policía (en su rol de guardiana de la seguridad pública) la que determina la magnitud de esa contratación.

Como señala Gabriel Kessler (2011), la gestión de la seguridad implica no solo la prevención del delito, sino principalmente la búsqueda de garantizar la percepción de un umbral aceptable de delitos y de las condiciones que generen en la comunidad un sentimiento de seguridad. En ese sentido, la gestión de la seguridad no implica necesariamente la anulación del delito ni de la violencia, sino la capacidad de brindar una percepción generalizada de seguridad, que no es necesariamente ficticia, pero que mantiene cierta autonomía con respecto al nivel de delitos y violencias. La policía en Argentina, como explica Esteban Rodríguez Alzueta (2014), participa de y regula los mercados ilegales, cobrando cánones que forman parte de las distintas cajas que se utilizan en las propias comisarías, y que llegan como último eslabón de la cadena a los altos funcionarios políticos. En el marco del fútbol, la policía participa de manera conjunta de mercados informales e ilegales, negociando con las «barras» y los dirigentes.

En el análisis de la reunión presentada en el comienzo de este artículo, recuperamos la experiencia que uno de nosotros tuvo cuando realizaba trabajo de campo con hinchadas, hace unos veinte ańos. En ese momento acompańamos a los miembros de la «barra» de un club argentino a una reunión en una comisaría. El encuentro con los policías fue amigable e incluyó un café con el comisario y los principales mandos de la policía. En ese marco, de conjunto, los «barras» y los policías organizaron el operativo de seguridad para el partido que el equipo por el que hinchaban esos «barras» jugaba el fin de semana siguiente de visitante. En esa oportunidad, el comisario estaba preocupado por la llegada de la «barra» a dicho 
estadio; en partidos pasados, cuando la «barra» pasaba frente a la tribuna popular local se producían incidentes varios. El policía, entonces, los convenció de hacer un recorrido más largo para llegar hasta el estadio, prometiéndoles a cambio que ingresarían con banderas, que en esos días estaban prohibidas. En su momento, entendimos que esa interacción era un ejemplo claro de la capacidad de las «barras» de usar prácticas violentas distintivas para sus intereses. Eso mostraba cómo, más allá de ser denominados por los medios como «los violentos» y ser señalados como irracionales, hacían un uso racional de la violencia. A ese análisis le podemos ahora agregar otra dimensión que aquí queremos desarrollar: los policías negocian — tras bastidores, clandestinamente, sottovoce — con las «barras».

Los policías desean más que nadie que el operativo sea exitoso. La categoría de «operativo exitoso» debería ser estudiada en profundidad, ya que no refiere a la ausencia de episodios violentos sino a su visibilidad. Un operativo exitoso es aquel donde el partido no se suspende ni aparece en los medios de comunicación vinculado con hechos de violencia. La consolidación de la problemática de la violencia en el fútbol como problema público implica la visibilización de las violencias por los medios de comunicación. Al mismo tiempo, esos discursos responsabilizan en parte al Estado por no prevenir la violencia y reclaman mayor presencia y efectividad policial, además de endurecimiento de las leyes y otras medidas punitivas. Por eso, los policías saben que cualquier disturbio ocasionado por la «barra» puede empañar su accionar y generarle a la institución un impacto político negativo. Tienen en claro que, en el ambiente del fútbol argentino, no solamente los miembros de las «barras» tienen prácticas violentas. Lo que también comprenden es que las prácticas violentas de esas «barras» se pueden predecir, que tienen un sentido, y que, por lo tanto, pueden ser prevenidas a partir de la negociación. Esa se transforma entonces en una herramienta fundamental para el éxito de los operativos. Para que esto sea posible, los policías quieren y pretenden que existan jefes en las «barras», para establecer un interlocutor que sea válido y les permita pactar, y que tenga la legitimidad para garantizar el control de sus compañeros y el cumplimiento de los acuerdos.

Cuando en una "barra» hay diferentes facciones o grupos que se disputan el poder, la negociación se enmaraña, y cuando no existe un jefe legítimo, la regulación de la violencia se dificulta. Por ello, ante las disputas por el poder que se desatan al interior de las «barras», la policía adopta — regularmente- dos posturas. A veces se mantienen al margen de los conflictos y las guerras intestinas a la espera de que una de las facciones prevalezca sobre las otras para erigirse en el interlocutor con el cual negociar. Otras veces toman partido por una facción, extremando el control sobre la otra con el fin de debilitarla. Los dirigentes de los clubes, por su parte, también pretenden la presencia de un liderazgo claro en la «barra» que garantice el «buen gobierno» en la gestión de los clubes. El pacto que ordena el gobierno 
de la seguridad se ve en claramente en la intervención, o en la falta de ella, frente a los conflictos internos de las «barras». Allí, tanto policías como dirigentes actúan favoreciendo a ciertos grupos para garantizar la gobernabilidad. La policía, particularmente, no busca reprimir las acciones delictivas. En cambio, pretende negociar acuerdos con las «barras» y los dirigentes para regular las violencias.

\section{LA LEGITIMIDAD DE LAS VIOLENCIAS}

Una de las tesis que guía nuestras reflexiones, y que compartimos con varios de los investigadores citados anteriormente consiste en señalar que las múltiples formas de violencia que tienen lugar en los estadios de fútbol argentinos no pueden ser reducidas pura y exclusivamente a la acción de las «barras». Otros actores también despliegan prácticas violentas de distinto tipo: futbolistas, dirigentes deportivos, simpatizantes que no forman parte de las «barras», periodistas, entrenadores. Para identificar esas violencias es preciso correrse de la mirada tradicional que lee a la violencia exclusivamente en términos de violencia física directa, y pensarla de manera más amplia. Así, la represión policial, los cánticos xenófobos, las burlas homofóbicas, los golpes entre futbolistas, las malas condiciones de aforo de los estadios, el hacinamiento en las tribunas, las triangulaciones económicas de dirigentes y muchas otras prácticas forman parte de este repertorio de acciones violentas de distinto signo. Sin embargo, pese a la recurrencia, la intensidad y el daño que varias de esas prácticas generan, es más factible que sean menos visibles y visibilizadas que la violencia generada por las «barras». En ese sentido, opera en el fútbol argentino una estigmatización de los grupos «barras bravas» desde los discursos dominantes (medios de prensa, funcionarios estatales), que los ubican como únicos productores de riesgo, en una operación discursiva que escamotea las violencias de otros actores.

En Argentina, casi la totalidad de los clubes poseen una «barra brava», que es el nombre que define al núcleo duro de la hinchada. Se trata de un grupo de hinchas organizados y militantes, que tiene a su cargo la gestión festiva del estadio y que es reconocido (y se autorreconoce) por la recurrencia de sus prácticas violentas. Las «barras» están organizadas de manera piramidal, y según su magnitud pueden tener estructuras organizativas complejas. Los clubes más importantes del país (Boca, River, Racing, San Lorenzo, Independiente, Rosario Central, Newell's, Estudiantes) tienen «barras» más numerosas y movilizan más personas, recursos y actividades que las de clubes menores. Sin embargo, las lógicas de funcionamiento de las «barras» dependen de una gran variedad de factores y no es reductible únicamente al modelo que predomina en los grandes clubes. Sin embargo, contamos con suficiente evidencia para hablar de una matriz organizativa común a todas las «barras» que está vinculada con la lógica del «aguante» violento (Alabarces, 2004; Moreira, 2005; 
Garriga, 2007; Gil, 2007; Cabrera, 2013; Czesli, 2013). El «aguante» funciona como principio organizador de estos grupos, ya que es el capital que determina las jerarquías internas, que habilita la búsqueda de recursos materiales y que promueve el deseo de reconocimiento simbólico a partir de la participación en enfrentamientos físicos. Desde la lógica de las «barras», la intervención en peleas y hechos violentos posee una fuerte positividad que las nutre de respeto y prestigio frente a sus pares. En este mismo sentido, la inacción violenta es percibida como una deshonra, y se equipara a la falta de valentía, de hombría y de honor.

Algo que define a las «barras» argentinas son las relaciones de intercambios que mantienen con múltiples actores de poder. A diferencia de los modelos clásicos de ultras y hooligans europeos, que poseían un perfil de outsiders, los hinchas organizados argentinos tienen lazos e interacciones con dirigentes de clubes, futbolistas, empresarios, políticos y entrenadores, entre otros actores sociales. Esos vínculos permiten a las «barras» obtener recursos económicos de distintas maneras: empleos fijos o temporarios, porcentajes de la venta de futbolistas, dinero como «colaboración", tickets para los partidos, viajes, etc.

Desde inicios del siglo XX se registran hechos de violencia (Frydenberg, 2011) alrededor del fútbol argentino, incluso aún antes de que la práctica de este deporte fuese profesional. La novedad a partir de los años 1990 es la aparición de una lógica legitimadora de esas prácticas violentas, basada en el «aguante» como precepto organizador y modo relacional en el fútbol. Así, las peleas, enfrentamientos y muertes, que en otros contextos serían insoportables, en el futbol son aceptados. La aprobación ambigua y contextual de las violencias por algunos periodistas y muchos futbolistas y dirigentes da cuenta de un doble estándar moral que tiene lugar entre los actores del fútbol argentino.

$\mathrm{El}$ «aguante» como brújula ética y moral de las hinchadas argentinas es un fenómeno que comienza en los años 1980 y conquista definitivamente las tribunas en la década de 1990, al calor de cambios estructurales de las sociedades latinoamericanas. Justamente, la interpretación del fenómeno de la violencia en el fútbol que hicimos en trabajos anteriores sostenía que esas transformaciones, en particular el llamado fin de la sociedad salarial (Castel, 2004) y el debilitamiento del Estado producto de la aplicación vernácula de las recetas neoliberales, era claves para pensar el problema.

En ese sentido, si bien a lo largo de toda la historia argentina es posible identificar grupos sociales que usaran la violencia como diacrítico, construidos por fuera de los valores convencionales, esas grupalidades no eran legítimas ni masivas y además cargaban con fuertes estigmas. El "guapo» tanguero es el mejor ejemplo de este tipo de figura: poseedor de una reputación peleadora y de temer, perdía sin embargo pregnancia fuera del arrabal. De acuerdo a esa lectura, el «aguante» 
aparecía como una novedad, ya que no podía ser reducido a la marginalidad económica y social, sino que debía ser pensado al calor de las identidades propias de la nueva sociedad post salarial.

Eduardo Archetti (2003) sostenía que existe una «zona libre», liminal, donde tanto el Estado como las grandes construcciones dadoras de identidad (la escuela, el trabajo) pierden su influencia como constructores identitarios. Siguiendo a Archetti, nuestra tesis para problematizar al «aguante» se basaba en ese diagnóstico: el debilitamiento del Estado en los últimos cuarenta años acrecentó el tamaño de las "zonas libres» capaces de funcionar como espacios constructores de identidad. Así, nuevas identidades prosperan en un escenario donde las identidades tradicionales perdieron pregnancia y centralidad. La educación, la familia y el trabajo ya no ordenan el mundo social como lo hacían décadas atrás, ya no generan redes de pertenencia para integrar a los actores sociales (Svampa, 2000; Kessler, 2004), y su desvalorización crea las condiciones para la legitimidad de las prácticas violentas.

La pérdida de centralidad de las tramas identitarias tradicionales favoreció la multiplicación de pequeñas comunidades que pasaron a funcionar como referencias identitarias principales, muchas de ellas vinculadas a consumos culturales o incluso a bienes mercantiles. La «barra brava» es una de esas pequeñas comunidades, a partir de la atracción que genera como espacio interpelador en los hinchas de fútbol. La validez del «aguante» violento es, entonces, el lento resultado de la legitimidad de las «barras» y de la legitimidad de la violencia: ambas legitimidades se construyeron al calor de las transformaciones del escenario social argentino. En paralelo al cambio social operado desde los ańos 1970, la violencia y las «barras» van ganando protagonismo en el mundo del fútbol. Aquí acontece algo extraordinario: las «barras» se valorizan al mostrar sus capacidades violentas y, al mismo tiempo se incluyen en relaciones para regular la propia violencia que como grupalidad legitiman.

En esta multiplicidad de interacciones, las «barras» se nutren de legitimidad y/o de recursos. Rescatamos para este trabajo los intercambios que mantienen con los policías y con los dirigentes de los clubes. Entendemos que para comprender la gestión de la seguridad en el fútbol debemos dar cuenta de los vínculos e interacciones entre estos actores. Nuestra tesis consiste en olvidar las nociones de oposición y confrontación para proponer que los tres vértices de este triángulo («barras», policías y dirigentes) participan en la construcción de un escenario de negociaciones e intercambios que deseamos caracterizar como de regulación de las violencias. Así, mientras no ocurran hechos excepcionales (incidentes violentos con mucha repercusión mediática, un cambio de mandos policiales o político, peleas internas dentro de la «barra») que alteren los pactos y acuerdos informales establecidos, podemos hablar de una determinada forma de regulación de las violencias alrededor del fútbol argentino, y de un gobierno de la seguridad basado en la negociación y la reciprocidad. 


\section{El TRIPLE PACTO Y LA REGULACIÓN DE LAS VIOLENCIAS}

Alberto Binder (2009) y Marcelo Sain (2008) introdujeron la idea del «doble pacto» para analizar el fenómeno de la seguridad/inseguridad en Argentina. El «doble pacto» consiste en un trato espurio que implica, por un lado, la delegación del gobierno de la seguridad en manos de la policía, y por otro lado, una relación de regulación del delito de los policías con las organizaciones criminales. El primer eslabón del pacto consiste en un acuerdo entre funcionarios políticos y policías: mientras que los políticos se aseguran el control del delito, la policía consigue autonomía para sus tareas cotidianas y también para la búsqueda de recursos (mediante coimas, protección, mercados ilícitos, etc.). La segunda parte del pacto se produce entre policías y delincuentes, y el resultado de ella es la regulación del delito. Según estos autores, aquí funciona una matriz ideológica, ya que los funcionarios políticos (sin diferencia de partido ni de nivel) le "entregan» a la policía el gobierno de la seguridad bajo la creencia de que sólo por intermedio de esta es posible solucionar el problema de la inseguridad.

En torno a la seguridad en el fútbol los pactos que intervienen en la gestión de la violencia tienen otros matices. Esta es, en cierta forma, el resultado de un pacto cotidiano entre policías, «barras bravas» y dirigentes deportivos, que a través de intercambios e interdependencias mutuas se vinculan entre sí. En muchos casos las partes desconocen - aunque imaginan - las relaciones que suceden en los otros vértices de este triángulo.

En Argentina, la gestión estatal de la violencia en el fútbol como problema público que debía ser atendido se cristaliza en 1985, cuando se sanciona la primera ley específica dedicada a los eventos futbolísticos. Ese punto de partida va a marcar en gran manera el abordaje que el Estado argentino hará del problema en las décadas siguientes: suponer que la violencia en el fútbol se soluciona meramente con el cumplimiento de la ley. En este artículo no vamos a profundizar sobre el accionar de los actores políticos y gubernamentales respecto de la violencia en el fútbol, sino que solo nos interesa señalar que éstos han tendido históricamente a delegar la gestión de la seguridad deportiva en la policía. Y lo han hecho por dos motivos: incapacidad y estrategia de invisibilización.

La incapacidad de la gestión política de la seguridad en el fútbol parte de suponer, como señalamos, que el imperio de la ley es la cura para todos los males. La recurrencia a elaborar una ley "que meta presos a todos los violentos» es una tentación en la que cayeron muchas de las administraciones estatales desde la década de 1980 hasta hoy. Sin dudas, las leyes son importantes para penar los delitos, pero el aura de legitimidad que rodea a las acciones violentas en el mundo del fútbol no se derriba solamente con leyes, sino con acciones que apunten a modificar la lógica cultural del fútbol argentino. Además, y de forma complementaria y negativa, la búsqueda 
de la ley perfecta esconde y opaca las múltiples relaciones (clandestinas, tras bambalinas) que existen entre los dirigentes políticos y las «barras».

Analizando las interacciones entre la policía, las «barras» y los dirigentes de los clubes de fútbol podemos señalar dos características que priman en sus relaciones: la invisibilidad y el intercambio. La invisibilidad aparece como condición necesaria para garantizar el éxito de los acuerdos y pactos, ya que en estos involucran mayormente condiciones que no se ajustan al orden normativo legítimo. Mientras que los intercambios responden a una reciprocidad basada en la mutua necesidad: lazos de interdependencia sobre un vínculo conflictivo.

Las interacciones entre la dirigencia deportiva y la policía se inscriben en un marco de regulaciones ambiguo, como es el de la gestión de la seguridad deportiva argentina. En cada estadio donde se juega un partido, el club local contrata los servicios de la policía pública, de la misma forma que si se tratara de una empresa de seguridad privada. Habilitada por el argumento de que el fútbol es un evento de alto riesgo que no puede quedar fuera de la órbita del Estado, se produce la privatización de la fuerza policial estatal. Bajo ese esquema, la policía mantiene su independencia en la toma de decisiones, ya que pese a estar rentada por un actor privado (club de fútbol), está en el estadio como representante del Estado, dando lugar a una gran paradoja. Este esquema ambiguo tiene beneficios para ambos actores: para la dirigencia de los clubes, la entrega del control de la seguridad a la policía redunda positivamente en que, en caso de algún conflicto, pueden desligar en el Estado (al menos discursivamente) la responsabilidad. Y su vez la policía se beneficia con el ingreso de dinero que suponen los «operativos» en los estadios, que constituyen una suculenta caja para las arcas de la institución policial.

La recepción que tiene entre los agentes policiales su labor en los estadios presenta diferentes posturas, que pudimos ir reconstruyendo a partir de diferentes entrevistas con policías a lo largo del tiempo. Algunos ven con buenos ojos esta tarea ya que les permite tener control sobre un espacio social preciado como el fútbol, otros la aceptan como forma de asegurar ingresos adicionales, y hay un porcentaje de agentes policiales que no la aceptan, pero están obligados a realizar el trabajo. Así, la relación entre dirigentes y policía es de mutua conveniencia, pero a la vez de control recíproco. La "caja» y el mutuo control vuelven invisible al pacto entre estos dos actores.

Las relaciones entre la policía y las «barras» tienen su anclaje en el espacio geográfico del estadio de fútbol, los días de partido. Ambos actores despliegan sus fuerzas en el estadio y sus inmediaciones para obtener distintos tipos de beneficios. Juntos organizan la logística del partido los días anteriores, definiendo los lugares de ingreso de la «barra», las banderas que les estarán permitidas ingresar, etc. Para la policía, el diálogo con «los radicalizados» — como se denomina a la «barra» 
en lenguaje policial - permite prever conflictos y conocer los estados de ánimo de la tribuna. Pero también la interacción tiene una contraparte económica, cuando la policía se «asocia» a la «barra» en varios de los negocios ilegales que esta lleva a cabo: control del estacionamiento de vehículos, control de puesto de comida y bebida, reventa de tickets.

Por su parte, para la «barra», mantener relaciones fluidas con la policía es sustancial para su perpetuación como grupo organizado. En este diálogo, la «barra» regula la gestión de los elementos ligados a la "fiesta» dentro del estadio (bombos, grandes banderas, etc.). Mantener el monopolio del control de estos elementos, prohibidos para el resto de los espectadores, proporciona a la "barra» buena parte de su legitimidad como actor principal de la tribuna. Y esa gestión no puede darse sin la negociación con la policía, que es quien determina lo que se puede ingresar al estadio y lo que no. Además, cabe repetir que la «barra» se favorece de su relación con la policía por la participación en economías ilegales e informales, muchas de las cuales se despliegan en el espacio del estadio y para las cuales es imprescindible contar con la indulgencia policial (control del estacionamiento, de los puestos de comida, ingreso al estadio, etc.).

Finalmente, la tercera parte del pacto se da entre dirigentes deportivos y «barra». Un ejercicio habitual de la gran mayoría de los dirigentes del fútbol argentinos consiste en negar públicamente todo tipo de relación con los miembros de la «barra brava» de sus clubes. La contracara de esa negación ocurre en privado: allí, dirigentes y «barras» comparten variadas interacciones: comidas, entrega de tickets o dinero, conexión con otras personas para satisfacer distintas necesidades. Los dirigentes deportivos se ven en la necesidad de dialogar y negociar con la «barra» para mantener bajo control el gobierno de sus instituciones, en la medida que la «barra» es en ocasiones un actor tan o incluso más poderoso que los dirigentes mismos. Una vez establecido ese vínculo, la intensidad que posee depende de cada caso particular, en un abanico que va desde la simple convivencia hasta la participación conjunta en actividades económicas informales e ilegales (reventa de tickets, amedrentamiento de futbolistas, transferencia de jugadores, etc.). A partir de ostentar ese vínculo, las «barras» ven allanado su camino para desplegar las actividades económicas que señalamos, así como también ven reforzado su rol protagónico como organizadores del ambiente festivo del estadio.

\section{LAS GRIETAS DEL PACTO}

Sin embargo, el pacto está lejos de funcionar como una receta infalible para asegurar el buen gobierno de la seguridad en los estadios. Con frecuencia ocurren incidentes, desbordes y hechos de violencia alrededor del fútbol que, si son acompañados por heridos, detenidos o muertos, pasan inmediatamente a ocupar las primeras planas 
de los medios de comunicación. Esos sucesos nos permiten ver que el pacto posee grietas y zonas de sombras cuyos efectos impredecibles dejan al descubierto su fragilidad como única estrategia de garantía del gobierno de la seguridad.

En primer término, debido a la ausencia de profesionalidad de las partes involucradas. Ni las «barras», ni las policías encargadas de la seguridad en espectáculos futbolísticos tienen altos grados de profesionalización. Las «barras» son una organización informal, con incapacidad para controlar a todos sus miembros. Y en el caso de las policías, sucede que los uniformados encargados de la seguridad no son los que capitalizan los beneficios ni simbólicos ni materiales de los mercados en torno al fútbol.

En segundo lugar, la fragilidad de los acuerdos radica en que la violencia sigue siendo el bien simbólico e identitario que ordena las jerarquías dentro de las «barras». Es a través de la violencia que los miembros de las barras construyen su identificación grupal. La violencia, a pesar de los cambios en estas agrupaciones, sigue siendo la práctica que ordena este mundo. Así, la regulación de las violencias, nunca y de ningún modo, puede acontecer íntegramente.

En tercer lugar, el pacto es frágil y falla porque las «barras» no son los únicos que acometen prácticas violentas. La policía, los dirigentes, los espectadores que no son parte de las «barras» tienen prácticas violentas. Las «barras» son el más visible de todos los actores del fútbol que tienen prácticas violentas, pero no los únicos.

El pacto exhibe un orden inestable que presume, erróneamente, que la administración de la seguridad puede ser efectiva "controlando» a las «barras». Olvida así otras tantas formas de violencias que pululan por el mundo del fútbol. Gran cantidad de violencias que son parte estructural del fútbol argentino. Tomemos como caso que ilumina esta cuestión el asesinato de Emanuel Balbo. El 17 de abril de 2017, dos días después de ser arrojado de una tribuna del estadio Mario Alberto Kempes, en Córdoba, durante el clásico que jugaban Belgrano y Talleres, falleció Emanuel Balbo ${ }^{5}$. Ese día, las fallas del pacto quedaron más que visibles. Emanuel fue acusado de infiltrado, de ser un hincha rival. Lo golpearon, lo empujaron desde lo alto de una boca de salida y celebraron su muerte mientras le robaban las zapatillas. Emanuel no fue golpeado por «barras», los hechos acontecieron lejos, muy lejos, de donde se ubica la "barra». A Emanuel lo asesinaron espectadores, hinchas no «barras». Aquellos que difícilmente sean asociados con las violencias. La negación de estas violencias oculta las grietas del pacto. Esa negación y ocultamiento explican la posibilidad de que un operativo y el propio pacto de regulación de las violencias funcionen correctamente y convivan con un asesinato en plena tribuna.

Belgrano y Talleres son los dos equipos más importantes de la provincia de Córdoba, tercera en densidad de población de la Argentina. El partido que juegan entre sí constituye el clásico más convocante de la provincia y uno de los más relevantes (tanto deportiva como culturalmente) del interior del país. 


\section{ConClusiones: El Estado y los MERCADOS ILEgALES}

Siguiendo a Gabriel Kessler (2014) y su diagnóstico sobre la Argentina contemporánea, podemos afirmar que en el período entre 2003 y 2013 existió un fortalecimiento del Estado en varias de sus dimensiones, un tenue recalentamiento del mundo del trabajo y una mejora — relativa — de los índices de calidad de vida. Las relaciones entre estas variables y la violencia en el fútbol parecen no tener la correlatividad que antes proponíamos. La mejora en diferentes índices sociales no apaciguó el tendal de muertos o incidentes que siguieron poblando los estadios de fútbol. El fortalecimiento del Estado tampoco disminuyó la legitimidad de la violencia. Observamos aquí la mediación cultural y su temporalidad sobre las variables estructurales. Pero nos cabe ensayar una respuesta asociada con nuestro análisis.

El pacto de regulación de la violencia persiste al ordenar un mercado que beneficia a las tres partes: «barras», dirigentes y policías. El pacto protege los negocios informales e ilegales desplegados alrededor del espectáculo. Es un pacto organizado en torno al mercado. Y sabemos que, para el funcionamiento de los mercados, sean formales, informales e incluso ilegales, no es funcional la existencia permanente de violencia a su alrededor. Para que un mercado funcione debe reinar un orden. Y lo que el pacto garantiza es un orden. Un orden paralelo, alternativo, clandestino, pero un orden al fin. Ese orden permite una cierta regulación de las violencias, especialmente de aquellas que pueden exponer públicamente el mal gobierno de la seguridad, permitiendo el desarrollo de los mercados en los que interactúan policías, «barras» y dirigentes. Así, la regulación de la violencia da el orden que necesita el mercado.

Además, el pacto fortaleza el lugar de las «barras» es, entre otras cosas, el resultado de la fortaleza del pacto de regulación. La prohibición de concurrencias para las parcialidades visitantes una de las medidas tomadas en los últimos años robustece el rol central de las «barras» en el mundo del fútbol. Nuestra hipótesis sugiere que, frente a la presencia real de una hinchada rival en el espacio del estadio, la «barra» desplegaba en cada partido elementos de la dimensión del aguante-violencia para confrontar con ese rival, caracterizado siempre como enemigo. La falta de rival no quita protagonismo a las «barra», ya que siguen teniendo un rol protagónico en la festividad de las tribunas. Además, como la lógica del aguante no se ha modificado con esta prohibición, siguen las barras capitalizando los beneficios de las violencias ahora más invisibles.

Para concluir, hemos señalado que la función que asume el pacto para el Estado —encarnado aquí en la policía- es, en primer lugar, asegurar el buen gobierno de la seguridad en el espacio del estadio de fútbol. Esto implica no sólo la capacidad de brindar seguridad sino también de mostrarlo. La exposición espectacular 
de los operativos policiales con miles de efectivos, nuevas tecnologías de control y vigilancia, permiten expresar un accionar estatal en la regulación de la seguridad, más allá de la eficacia de los mismos. Pero, además, la intervención policial combina el control informal de la criminalidad con la extracción de recursos económicos a partir de actividades para las que se asocia a la «barra». Entonces, nos interesa, subrayar que el Estado, aquí representado en las policías, es garante, por delegación de los poderes políticos, de la regulación del mercado informal del fútbol.

\section{REFERENCIAS}

Alabarces, P. (2004). Crónica del aguante. Fútbol, violencia y politica. Buenos Aires: Capital Intelectual.

Archetti, E. (1992). ¿Calcio: un ritual di violenza? En P. Lanfranchi (ed.), II calcio e il suo pubblico. Nápoles: Edizione Scientifiche Italiane.

Archetti, E. (2003). Masculinidades: fútbol, tango y polo en la Argentina. Buenos Aires: Antropofagia.

Binder, A. (2009). El control de la criminalidad en una sociedad democrática. Ideas para una discusión conceptual. En G. Kessler (comp.), Seguridad y ciudadanía: nuevos paradigmas, reforma policial y politicas innovadoras. Buenos Aires: Edhasa.

Cabrera, N. (2015). La metamorfosis de la violencia: viejos y nuevos interrogantes para el escenario actual del fútbol argentino. Ponencia presentada en la XI RAM: Reunión de antropología del Mercosur 2015, realizada del 30 de noviembre al 4 de diciembre del 2015, Universidad de la República, Facultad de Humanidades y Ciencias de la Educación (UDELAR), Montevideo.

Cabrera, N., Czesli, F. y Garriga Zucal, J. (2016). El aguante en el debate: violencia en el fútbol y políticas públicas en la Argentina. Esporte e Sociedade, 27, año 11, Universidad Federal Fluminense, NEPESS, 1- 29.

Castel, R. (2004). La inseguridad social: ¿qué es estar protegido? Buenos Aires: Manantial.

Csezli, F. (2013). Apuntes sobre la identidad en la hinchada de Platense. En J. Garriga Zucal (comp.), Violencia en el fútbol: Investigaciones sociales y fracasos politicos (pp. 95-125). Buenos Aires: Godot.

Frydenberg, J. (2010). Historia social del fútbol. Buenos Aires: Siglo XXI.

Garriga Zucal, J. (2007). Haciendo amigos a las piñas. Violencia y redes sociales de una hinchada de fútbol. Buenos Aires: Prometeo.

Gil, G. (2007). Hinchas en tránsito. Violencia, memoria e identidad en una hinchada de un club del interior. Mar del Plata: Eudem.

Kessler, G. (2004). Sociología del delito amateur. Buenos Aires: Paidós.

Kessler, G. (2011). El sentimiento de inseguridad. Sociología del temor al delito. Buenos Aire: Siglo XXI.

Kessler, G. (2014). Controversias sobre la desigualdad. Buenos Aires: Fondo de Cultura Económica. 
Moreira, M. V. (2005). Trofeos de guerra y hombres de honor. En P. Alabarces (ed.), Hinchadas (pp 75-89). Buenos Aires: Prometeo.

Murzi, D. (2019). Fútbol, violencia y Estado. Un estudio sobre las políticas públicas de seguridad deportiva en Argentina (2006-2017). Tesis doctoral inédita (defendida en marzo de 2019 en la Facultad de Ciencias Sociales de la Universidad de Buenos Aires).

Murzi, D.; Uliana, S. y Sustas, S. (2011). El fútbol de luto. Análisis de los factores de muerte y violencia en el fútbol argentino. En M. Godio y S. Uliana (eds.), Fútbol y sociedad. Prácticas locales e imaginarios globales (pp. 175-196). Buenos Aires: Eduntref.

Rodríguez Alzueta, E. (2014). Temor y control. La gestión de la inseguridad como forma de gobierno. Buenos Aires: Futuro Anterior.

Rosa, S. (2017). La década sin visitantes. Un análisis de los discursos sobre la prohibición del público visitante en el fútbol argentino (tesis de grado). Presentada en Universidad Nacional de La Plata. Facultad de Humanidades y Ciencias de la Educación para optar al grado de licenciado en Sociología. Disponible en: http://www.memoria. fahce.unlp.edu.ar/tesis/te.1335/te.1335.pdf

Saín, M. (2008) El leviatán azul. Policía y politica en la Argentina. Buenos Aires: Siglo XXI.

Svampa, M. (2000). Desde abajo. La transformación de las identidades sociales. Buenos Aires: Biblos. 